\title{
Central retinal artery occlusion as the presenting sign of essential thrombocythemia
}

\author{
Eansiyel trombositeminin başvuru belirtisi olarak santral retinal arter tıkanıklı̆̆l
}

\author{
Gül Arıkan¹, Ali Osman Saatci¹, Selda Kahraman², Özden Pişkin², \\ Süleyman Men ${ }^{3}$, Bülent Ündar² \\ ${ }^{1}$ Dokuz Eylül University, School of Medicine, Department of Ophthalmology, Izmir, Turkey \\ ${ }^{2}$ Dokuz Eylül University, School of Medicine, Department of Hematology, Izmir, Turkey \\ ${ }^{3}$ Dokuz Eylül University, School of Medicine, Department of Radiology, Izmir, Turkey
}

\section{To the Editor,}

Essential thrombocythemia (ET) is a myeloproliferative disorder characterized by an elevated platelet count without an obvious cause. In addition to overproduction, platelets are also functionally abnormal; therefore, thromboembolic and hemorrhagic complications can occur in such patients [1]. Reports of retinal arterial occlusion [2,3] and venous occlusion [4-9] in cases with ET are rare. Herein we report a male patient with unilateral central retinal artery occlusion (CRAO) as the presenting sign of previously undiagnosed ET.

A 28-year-old male presented due to painless loss of vision in his right eye that began $6 \mathrm{~h}$ earlier. His medical history was unremarkable, except for smoking. On examination, visual acuity was no light perception in the right eye and 20/20 in the left eye. Ocular motility was full. A right afferent pupillary defect was noted. Intraocular pressure was 14 $\mathrm{mmHg}$ OU. Slit lamp examination results were unremarkable. Fundus examination of the right eye showed massive retinal opacification, markedly attenuated arteries, a box-car appearance in the retinal arterioles, and a cherry-red spot in the macula without emboli (Figure 1). The left fundus was normal. Anterior chamber paracentesis was performed in a surgical suite immediately following the diagnosis of CRAO. Written informed consent was obtained from the patient.

A thorough medical examination was carried out to clarify the etiology of CRAO. Carotid Doppler ultrasonography showed complete occlusion of the right common carotid artery (CCA) and internal carotid artery (ICA). Computed tomographic angiography also showed total occlusion of the right CCA and ICA, as well as retrograde filling of the intracranial portion of the right ICA from the anterior communicating artery (Figure 2). Echocardiography was normal. Abdominal ultrasonography showed splenomegaly. The patient's platelet count was $>1,000,000 \mathrm{~mm}^{-3}$ (normal range: 156,000-373,000 $\mathrm{mm}^{-3}$ ) in consecutive assays. White blood cell count was $8500 \mathrm{~mm}^{-3}$, hemoglobin was $16.2 \mathrm{~g} \mathrm{dL}^{-1}$, 


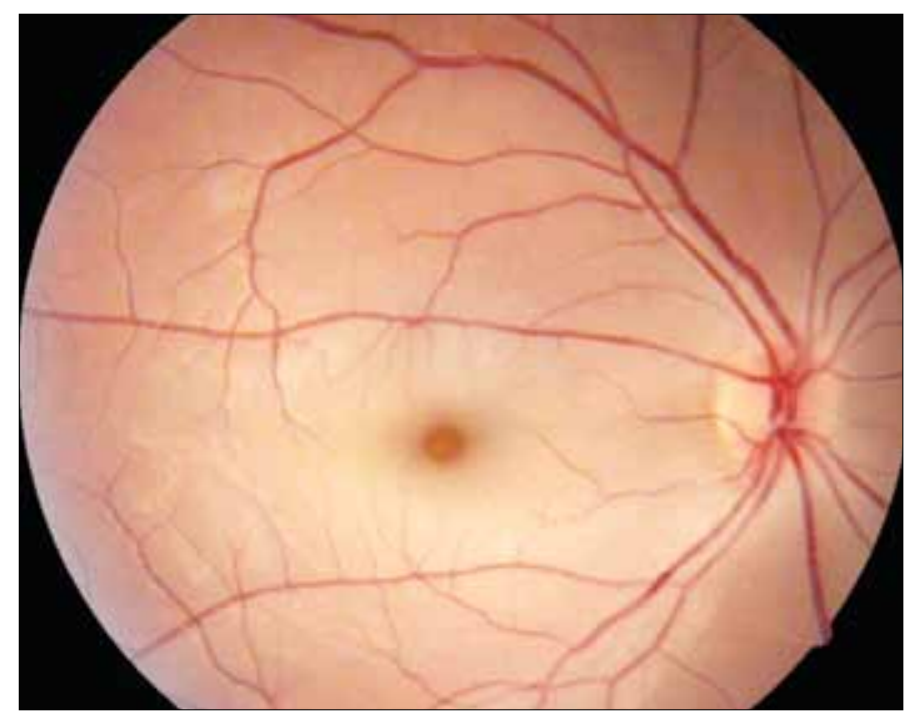

Figure 1. The fundus of the right eye at presentation shows the cherry-red spot and attenuated arterioles

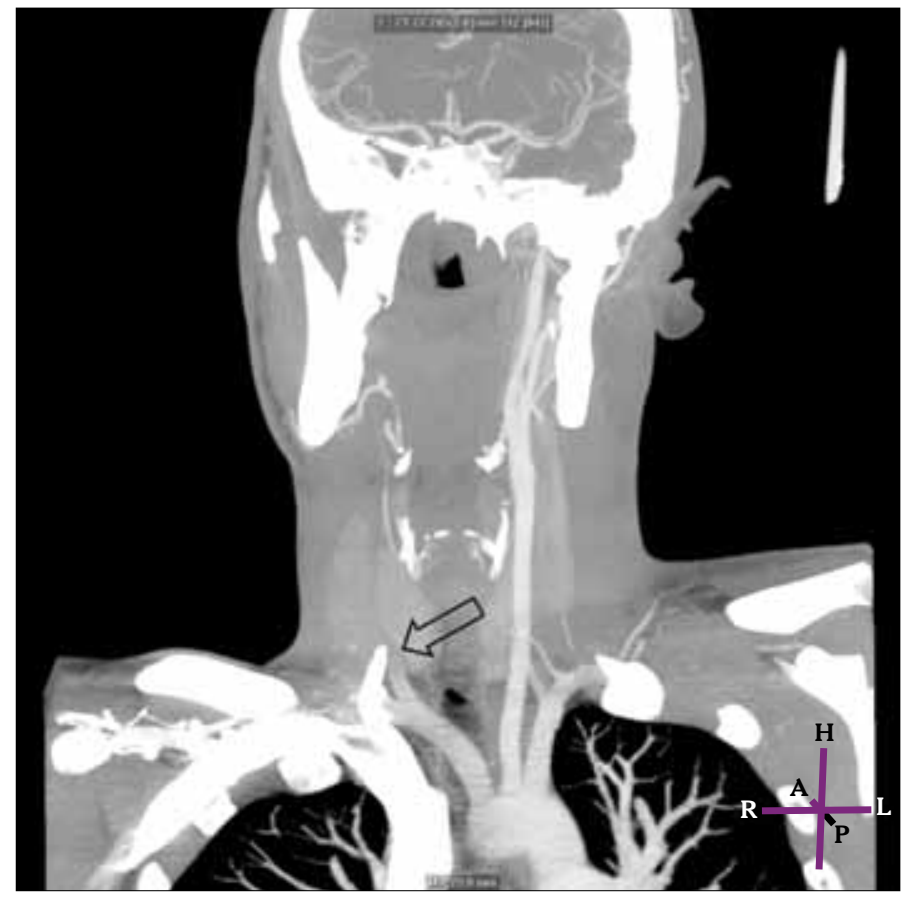

Figure 2. Coronal oblique computed tomographic angiography of the entire supra-aortic region. The right common carotid artery is occluded $2 \mathrm{~cm}$ distal to its origin (arrow). The right internal carotid artery is also occluded; right intracranial carotid circulation is provided by collateral pathways

hematocrit was 48.3\%, mean corpuscular volume was $88 \mathrm{fL}$, and ferritin was $58 \mathrm{ng} \mathrm{mL}^{-1}$.

Coagulation tests showed prothrombin 20210A gene mutation heterozygosity. Protein $\mathrm{C}$, protein $\mathrm{S}$, antithrombin III, serum homocysteine, activated protein $\mathrm{C}$ resistance, lupus anticoagulant, ANA, antiDS DNA, anticardiolipin IGM and IGG antibody, and sedimentation and $C$ reactive protein test results were within normal limits. Factor V Leiden mutation was negative. Peripheral blood smear showed abundant platelet clumps, and bone marrow biopsy showed megakaryocytic hyperplasia and reticulin fibrosis (grade 1). The patient was heterozygous for JAK 2 mutation and was Philadelphia chromosome negative. Cytogenetic analysis showed that the patient's karyotype was normal. The patient was diagnosed as ET. The patient subsequently stopped smoking, and hydroxyurea therapy and low-dose aspirin were initiated. The patient's platelet count returned to normal after 1 month of the treatment. Unfortunately, his visual acuity did not improve and he was lost to follow-up due to relocation to another city.

CRAO is a very rare clinical presentation in younger ages and a thorough systemic investigation is required to determine the underlying cause [10]. The pathogenesis of CRAO was not clear in the presented case. Embolism-despite no visible emboli-or thrombosis due mainly to ET might have been the cause; however, this patient, who was a smoker, had prothrombin 20210A mutation heterozygosity in addition to previously undiagnosed ET, and it is likely that the combined effect of these factors might have contributed to serious carotid stenosis and subsequent CRAO.

A PubMed search showed that only 2 cases of retinal arterial occlusion associated with ET have been published [2,3]. Singer [2] reported a 37-yearold male with recurrent attacks of migrating emboli in the retinal arteries that were associated with amaurosis fugax; he was subsequently diagnosed as ET. Strassman et al. [3] reported an elderly woman with unilateral CRAO that had been diagnosed as ET before. Clear carotid artery stenosis was not observed, but echocardiography showed a thickened calcific aortic valve. The researchers thought that platelet thrombi caused CRAO, but that an embolus coming from the calcified aortic valve could not be ruled out as a possible cause. Retinal venous occlusion was also reported in patients with ET [4-9]; in some cases venous vascular occlusion was unilateral [4-7] and in others it was bilateral [8,9]. Venous occlusion might also present as multiple occlusions in the same eye [8].

ET is among the underlying hematologic disorders in patients with CRAO. Our aim was to share our observations with the ophthalmic and hematologic communities, and to increase the awareness of the possible etiological role of ET in CRAO. 


\section{Conflict of interest statement}

The authors of this paper have no conflicts of interest, including specific financial interests, relationships, and/or affiliations relevant to the subject matter or materials included.

\section{References}

1. Spivak JL. Polycythemia vera and other myeloproliferative diseases. In: Fauci AS, Braunwald E, Isselbacher KJ, Wilson JD, Martin JB, Kasper DL, Hauser SL, Longo DL, eds. Harrison's Principles of Internal Medicine. 14th ed. New York: McGraw-Hill , 1991;683-4.

2. Singer G. Migrating emboli of retinal arteries in thrombocythaemia. Br J Ophthalmol 1969;53:279-81. [CrossRef]

3. Strassman I, Silverstone BZ, Seelenfreund MH, Sheer A, Berson D. Essential thrombocythemia: a rare case of central retinal artery occlusion. Metab Pediatr Syst Ophthalmol 1991;14:18-20.

4. Yoshizumi MO, Townsend-Pico W. Essential thrombocythemia and central retinal vein occlusion with neo- vascular glaucoma. Am J Ophthalmol 1996;121:728-30.

5. Nobacht S, Cruysberg JR, Deutman AF. Peripheral retinal nonperfusion associated with essential thrombocytosis. Am J Ophthalmol 1999;127:101-2. [CrossRef]

6. Asensio Sánchez VM, Manteca Jiménez G, Cano Navarro E. Essential thrombocythemia and retinal vein thrombosis. Arch Soc Esp Oftalmol 2004;79:629-32. [CrossRef]

7. Tache JE, Saffra N, Marshak H, Aithal S, Novetsky A, Huang YW. Retinal vein thrombosis as the presenting symptom of essential thrombocythemia. Am J Med Sci 2005;329:139-40. [CrossRef]

8. Imasawa M, lijima $\mathrm{H}$. Multiple retinal vein occlusions in essential hrombocythemia. Am J Ophthalmol 2002;133:152-5. [CrossRef]

9. Liu M, Lee AG, Rice L, Lambert HM. Bilateral retinal vascular occlusive disease in essential thrombocythemia. Retina 1999;19:563-4. [CrossRef]

10. Brown GC, Magargal LE, Shields JA, Goldberg RE, Walsh PN. Retinal arterial obstruction in children and young adults. Ophthalmology 1981;88:18-25. 